\title{
A tribo Microlicieae (Melastomataceae) no estado do Paraná
}

\author{
Tribe Microlicieae (Melastomataceae) in the state of Paraná
}

\author{
Renato Goldenberg ${ }^{1,4}$, Lucas Freitas Bacci ${ }^{2} \&$ Juliana Wilgozz Moraes ${ }^{3}$
}

\begin{abstract}
Resumo
Os gêneros Chaetostoma, Lavoisiera, Microlicia, Rhynchanthera e Trembleya são os representantes da tribo Microlicieae no estado do Paraná, com nove espécies: C. armatum, L. imbricata, L. pulchella, M. myrtoidea, $R$. brachyrhyncha, R. cordata, R dichotoma, T. parviflora e T. phlogiformis. Neste trabalho foi elaborado o tratamento taxonômico para as espécies de Microlicieae no estado, com chaves de identificação, descrições morfológicas, comentários, ilustrações e informações sobre distribuição geográfica das espécies, além da lista de materiais examinados.
\end{abstract}

Palavras-chave: Chaetostoma, Lavoisiera, Microlicia, Rhynchanthera, taxonomia, Trembleya.

\begin{abstract}
The genera Chaetostoma, Lavoisiera, Microlicia, Rhynchanthera and Trembleya in the tribe Microlicieae occur in the state of Paraná, with nine species: C. armatum, L. imbricata, L. pulchella, M. myrtoidea, $R$. brachyrhyncha, R. cordata, R dichotoma, T. parviflora and T. phlogiformis. We present a taxonomic treatment for the species of Microlicieae for the state, with identification keys, descriptions, comments, drawings, information on geographic distribution and specimen lists.
\end{abstract}

Key words: Chaetostoma, Lavoisiera, Microlicia, Rhynchanthera, taxonomy, Trembleya.

\section{Introdução}

A família Melastomataceae Juss. possui 150166 gêneros e 4.200-4.500 espécies, distribuídas ao longo das regiões tropicais do globo (Renner 1993; Clausing \& Renner 2001), com 66 gêneros e 1360 espécies no Brasil (Goldenberg et al. 2012a; Baumgratz et al. 2014). Microlicieae é uma das 10 tribos reconhecidas na classificação infrafamilial atualmente utilizada (Renner 1993; Penneys et al. 2010). Tradicionalmente a tribo vinha sendo reconhecida com 15 gêneros (Cogniaux 1883$1885,1891)$ e depois 11 (Renner 1993), dos quais vários foram recentemente excluídos por não apresentarem relação filogenética com os demais, como Bucquetia DC., Cambessedesia DC., Castratella Naudin, Eriocnema Naudin e Lithobium Bongard (Fritsch et al. 2004; Amorim et al. 2009; Michelangeli et al. 2013;
Goldenberg et al. 2012b). Com a transferência destes gêneros para outras tribos, restaram apenas seis, que podem ser reconhecidos pelas sementes reniformes, elipsoides ou alongadas, com testa foveolada ou lacunosa-reticulada (Fritsch et al. 2004). A maior parte das espécies possui estames dimórficos, com conectivo prolongado abaixo das anteras, e estas apresentam ápice rostrado, mas há exceções, como em Stenodon Naudin. Este último gênero é o único da tribo que não ocorre no Paraná (Martins \& Rodrigues 2014c). Os demais, Chaetostoma DC., Lavoisiera DC., Microlicia D.Don, Rhynchanthera DC. e Trembleya DC. são tratados a seguir. São apresentados chaves de identificação, descrições dos gêneros e espécies, comentários, distribuição geográfica, listagens de materiais examinados e ilustrações para todas as espécies destes gêneros no estado.

\footnotetext{
Universidade Federal do Paraná, Centro Politécnico, Depto. Botânica, sl. 447, C.P. 19031, 81531-970, Curitiba, PR, Brasil.

${ }^{2}$ Universidade Federal do Paraná, Centro Politécnico, Depto. Botânica, C.P. 19031, 81531-970, Curitiba, PR, Brasil.

${ }^{3}$ Universidade Federal do Paraná, Centro Politécnico, Curso de Ciências Biológicas, C.P. 19031, 81531-970, Curitiba, PR, Brasil.

${ }^{4}$ Autor para correspondência: rgolden@ufpr.br
} 


\section{Materiais e Métodos}

As exsicatas analisadas neste trabalho foram provenientes dos herbários EFC, FUEL, HUCP, MBM, RB, UPCB (siglas segundo Thiers continuously updated). As amostras listadas como "material selecionado" ou "material examinado" foram exclusivamente provenientes do estado do Paraná e serviram de base para as descrições. $\mathrm{O}$ material foi selecionado quando havia mais de uma coleta no município. Neste caso, todas as amostras podem ser conferidas na lista de exsicatas, ao final do trabalho. As amostras listadas como "material adicional examinado" foram provenientes de outros estados, quando houve necessidade de mais materiais para complementar as descrições. As descrições da tribo e dos gêneros foram baseadas nas características encontradas para as espécies ocorrentes no Paraná.

Para mais informações sobre os táxons tratados aqui, como listagens de sinonímias e tipos, ver Renner (1990), Koschnitzke \& Martins (2006) e Martins (1997). Estes mesmos trabalhos, e mais os tratamentos sobre cada gênero na "Flora Fanerogâmica de São Paulo" (Martins 2009a) e na Lista do Brasil" (Baumgratz et al. 2014) foram consultados para informações sobre distribuição geográfica. Os dados sobre fenologia foram obtidos a partir de exemplares coletados no Paraná e depositados em herbários.

Para dados sobre o ambiente físico e vegetação do Paraná ver Maack (1968) e Labiak (2014). Estes autores reconhecem cinco regiões ou paisagens naturais: Litoral, Serra do Mar, Primeiro, Segundo e Terceiro Planaltos. Ao longo destas regiões ocorrem cinco tipos de vegetação: 1. Floresta Ombrófila Densa, na Serra do Mar e Litoral, onde podem ser reconhecidos quatro subtipos (florestas Altomontana, Montana, Submontana e de Terras Baixas) e mais formações associadas (campos de altitude, restingas e manguezais); 2. Floresta Ombrófila Mista, em áreas mais altas sobre os três planaltos; 3. Estepe Ombrófila (Campos Gerais), também em áreas mais altas, sobre os planaltos; 4. Floresta Estacional Semidecidual (nas porções norte e oeste do Segundo e Terceiro Planaltos); 5. Savana Estacional Subxérica (Cerrado), no centro e nordeste do estado.

\section{Resultados e Discussão}

As características mais comuns aos gêneros de Microlicieae são o hábito geralmente arbustivo, folhas frequentemente pequenas, estames com pedoconectivos, e sementes ovoides ou oblongas com superfície geralmente foveolada (Renner 1993). A tribo conta com nove espécies no Paraná, pertencentes a cinco gêneros. $\mathrm{O}$ estado é o limite setentrional de quatro destes gêneros: Cambessedesia, Lavoisiera, Microlicia e Trembleya. Apenas Rhynchanthera ocorre mais ao sul, em Santa Catarina, com as mesmas três espécies que ocorrem no Paraná. Esta diminuição do número de espécies de Microlicieae em um sentido norte-sul fica mais clara quando se considera que $o$ estado exatamente ao norte, São Paulo, apresenta 23 espécies pertencentes à tribo (Martins 2009a). Esta diferença na composição da tribo em São Paulo e Paraná se deve, principalmente às nove espécies de Microlicia e oito de Rhynchanthera encontradas em São Paulo.

\section{Tratamento taxonômico}

Microlicieae Naudin, Ann. Sci. Nat. Ser 3. Bot. 12: 203. 1849.

Arbustos, raro ervas, cespitosos ou eretos, com indumento variado. Folhas imbricadas ou não, sésseis ou subsésseis a pecioladas, planas, acródromas, geralmente sem pontuações translúcidas (presentes em Microlicia e algumas espécies de Trembleya). Flores 5-6-meras, solitárias ou em inflorescências, terminais ou laterais. Estames em dois ciclos, estes dimórficos ou raramente subisomórficos (Chaetostoma), raramente com um ciclo reduzido a estaminódios (Rhynchanthera); filete glabro; conectivo prolongado abaixo das tecas, com apêndices ventrais; antera com ápice rostrado ou não (Chaetostoma), com poro ventral. Hipanto sem ou com coroa de tricomas no ápice (Chaetostoma). Ovário livre ou parcialmente adnato ao hipanto, 3-6-locular, placentação axilar, ápice glabro; estilete glabro ou com tricomas glandulares esparsos. Fruto capsular; sementes numerosas, ovoides ou oblongas.

\section{Chave de identificação para as espécies paranaenses da tribo Microlicieae}

1. Hipanto com coroa de tricomas no ápice; anteras com o ápice atenuado, não rostrado......

1'. Hipanto sem coroa de tricomas no ápice; anteras com o ápice rostrado 1.1. Chaetostoma armatum 
2. Estames 5, com mais 5 estaminódios

3. Estames férteis subisomórficos (todos com o mesmo tamanho)

4.3. Rhynchanthera dichotoma

3'. Estames férteis dimórficos (um estame distintamente maior que os demais)

4. Folhas sésseis ou subsésseis (pecíolos com até $4 \mathrm{~mm}$ compr.)

4'. Folhas pecioladas (pecíolos acima de $6 \mathrm{~mm}$ compr.) 4.1. Rhynchanthera brachyrhyncha

2'. Estames 10-12, estaminódios ausentes

5. Folhas com pontuações translúcidas; ovário 3-locular 4.2. Rhynchanthera cordata

5'. Folhas sem pontuações translúcidas; ovário 4-6-locular

6. Folhas 5-15 × 3-7 mm; flores geralmente 6-meras (raramente 5-meras); pétalas lilases ou magenta

7. Folhas 5-8 $\times 3-4 \mathrm{~mm}$, margem densamente ciliada.

2.1. Lavoisiera imbricata

7'. Folhas 9-15 × 4-7 mm, margem esparsamente ciliada .........2.2. Lavoisiera pulchella

6'. Folhas 23-50 × 6-16 mm; flores 5-meras; pétalas brancas ou rosadas

8. Folhas discolores; pétalas brancas

5.1. Trembleya parviflora

8'. Folhas concolores; pétalas rosadas.

5.2. Trembleya phlogiformis

1. Chaetostoma DC., Prodr. 3: 112. 1828.

Arbustos cespitosos. Folhas imbricadas, sésseis, sem pontuações translúcidas. Flores isoladas, 5-meras. Hipanto com coroa de tricomas no ápice. Pétalas rosadas ou lilases. Estames 10, subisomórficos, estaminódios ausentes; antera com ápice subulado. Ovário 3-locular, livre; estilete glabro.

Chaetostoma é um gênero exclusivamente brasileiro, com 11 espécies. Tem distribuição predominante em formações rupestres de Minas Gerais, Goiás e Distrito Federal, ocorrendo também no Mato Grosso, Bahia, Rio de Janeiro, São Paulo e Paraná. No Paraná é representado por uma espécie (Koschnitzke \& Martins 2006; Koschnitzke 2009; Martins et al. 2014a).

1.1 Chaetostoma armatum (Spreng.) Cogn. in Mart., Eichl. \& Urban, Fl. bras. 14: 31. 1883.

Fig. 1a-c

Arbustos 0,3-0,6 m alt. Ramos jovens cilíndricos, glabros ou com tricomas pedunculadoestrelados. Lâmina foliar 3-7×1-2 mm, coriácea, triangular-lanceolada, base semiamplexicaule, ápice agudo, margem serrilhado-ciliada a inteira, 5-7 nervuras basais, nervura central calosa; face adaxial glabra, face abaxial com tricomas simples esparsos sobre a nervura central. Flores terminais. Hipanto 3-5 × 2-3 mm, campanulado, glabro mas com coroa de tricomas $0.9-1,6 \mathrm{~mm}$ compr. no ápice. Cálice com lacínias 2,6-4,2 mm compr., triangulares, ápice agudo, margem inteira, glabras. Pétalas ca. $8 \times 5 \mathrm{~mm}$, irregularmente obovadas, com apículo terminal, glabras. Estames maiores com filete 4,3-6,4 mm compr., conectivo $0,5-0,8$ mm compr., com apêndices $0,2-0,4 \mathrm{~mm}$ compr.; estames menores com filetes 1,9-3,6 mm compr., conectivo 0,4-0,5 mm compr., com apêndices ca. 0,1 mm compr. Ovário 3-4 mm compr., ápice cônico, lobado; estilete 8-11 mm compr. Cápsula ca. $5 \times 3 \mathrm{~mm}$; sementes $0,6-0,7 \times 0,3 \mathrm{~mm}$.

Material selecionado: Arapoti, 21.III.1968, G. Hatschbach 18856 (MBM, UPCB); Jaguaraiva, 26.IX.2009, M.K. Caddah 671 (UPCB); Piraí do Sul, 29.IV.2012, R. Goldenberg 1653 (RB, UPCB); Ponta Grossa, 20.II.2003, O.S. Ribas 5036 (MBM); Sengés, 28.II.1972, G. Hatschbach 29249 (MBM); Tibagi, 27.X.2005, R. Goldenberg 819 (MBM, UPCB); Ventania, 9.VI.2005, D.A. Estevan 1020 (MBM).

Chaetostoma armatum é encontrada em Goiás, Bahia, Minas Gerais, São Paulo e Paraná (Koschnitzke \& Martins 2006; Martins et al. 2014a). Ocorre no Segundo Planalto paranaense. Geralmente coletada sobre solos arenosos, em regiões próximas a afloramentos de arenito. Coletada com flores de dezembro a julho; com frutos de novembro a junho.

2. Lavoisiera DC., Prodr. 3: 102. 1828.

Arbustos eretos. Folhas imbricadas ou não, sésseis, sem pontuações translúcidas. Flores isoladas; 5-6-meras. Hipanto sem coroa de tricomas no ápice. Pétalas lilases ou magenta. Estames 10-12, dimórficos, estaminódios ausentes; antera com ápice rostrado. Ovário 4-6-locular, parcial a totalmente adnato ao hipanto; estilete glabro. 
Lavoisiera é um gênero exclusivamente brasileiro, com 31 espécies. Tem distribuição predominante em formações rupestres de Minas Gerais, além de Bahia e Goiás, e mais raramente no Espírito Santo, Rio de Janeiro, São Paulo e Paraná. Neste último é representado por duas espécies. (Martins 2009b; Martins \& Rodrigues 2014a).

2.1 Lavoisiera imbricata (Thunb.) DC., Prodr. 3: 103. 1828.

Arbustos 0,3-1,5 m alt. Ramos jovens cilíndricos a obscuramente quadrangulares, tricomas simples ou pedunculado-estrelados. Lâmina foliar 5-8 × 3-4 mm, coriácea, oblongo-lanceolada, base semiamplexicaule, ápice cuspidado, margem calosa, inteira e densamente ciliada, 3 nervuras basais, nervura central calosa; face adaxial glabra, face abaxial geralmente glabra ou com tricomas simples e glandulares apenas sobre a nervura central. Flores terminais, 6-meras. Hipanto 3-4× 3-5 mm, campanulado, com tricomas glandulares esparsos. Cálice com lacínias 2,7-4,6 mm compr., obovadas, ápice mucronado com um tricoma, margem serreado-ciliada, glabras. Pétalas 11-15 $\times$ 6-11 mm, obovadas, ápice truncado com apículo terminal. Estames 12; estames maiores com filete 6-7,1 mm compr., conectivo 2,2-3,7 mm compr., com apêndices 1,1-1,6 mm compr., antera 2,5-3,1 mm compr.; estames menores com filetes $4,8-5,9$ mm compr., conectivo $0,7-1,4 \mathrm{~mm}$ compr., com apêndices $0,4-0,5 \mathrm{~mm}$ compr., antera ca. $2,5 \mathrm{~mm}$ compr. Ovário 2-4 mm compr., 6-locular, 1/2 a 2/3 adnato ao hipanto, ápice cônico; estilete $4-5 \mathrm{~mm}$ compr. Cápsula 4-6 × 4-5 mm; sementes 0,6-0,7 $\times$ ca. $0,3 \mathrm{~mm}$.

Material selecionado: Arapoti, 12.I.1973, G. Hatschbach 31164 (MBM); Jaguariaíva, 9.II.1997, O.S. Ribas 1652 (MBM); Piraí do Sul, 29.V.2012, $R$. Goldenberg 1651 (RB, UPCB); Sengés, 8.IV.1995, A.B. Espindola 9 (MBM); Tibagi, 27.X.2005, R. Goldenberg 820 (MBM, UPCB); Ventania, 22.III.2005, D.A. Estevan (UPCB 50642).

Lavoisiera imbricata é encotrada em Goiás, Distrito Federal, Bahia, Minas Gerais, Espírito Santo, Rio de Janeiro, São Paulo e Paraná (Martins 2009b; Martins \& Rodrigues 2014a). Ocorre no Segundo Planalto paranaense. Geralmente coletada sobre solos arenosos, em regiões próximas a afloramentos de arenito. Coletada com flores de janeiro a novembro, com frutos durante praticamente todo o ano.
2.2 Lavoisiera pulchella Cham., Linnaea 9: 370. 1834.

Fig. 1d-f

Arbustos 0,2-1,5 m alt. Ramos jovens cilíndricos a obscuramente quadrangulares, tricomas pedunculados-estrelados. Lâmina foliar 9-15 × 4-7 mm, coriácea, oblongo-lanceolada, base arredondada, ápice agudo, margem levemente calosa, inteira e esparsamente ciliada, 3 nervuras basais, nervura central calosa; face adaxial glabra, face abaxial com tricomas simples e glandulares sobre as nervuras central e laterais. Flores terminais, (5-)6-meras. Hipanto 4-6 × 3-4 $\mathrm{mm}$, estreitamente campanulado, com tricomas glandulares esparsos. Cálice com lacínias 5,2-9,5 $\mathrm{mm}$ compr., triangular-lanceoladas, ápice agudo e apiculado, margem inteira, glabras. Pétalas 11-21 $\times 7-10 \mathrm{~mm}$, obovadas, ápice truncado com apículo terminal. Estames 10-12; estames maiores com filete 5,5-7,1 mm compr., conectivo 3,5-4,8 mm compr., com apêndices 1-2,2 mm compr., antera 3-5 mm compr.; estames menores com filete 4,6-5,9 mm compr.; conectivo 0,7-1,2 mm compr., com apêndices ca. $0,4 \mathrm{~mm}$ compr., antera 2,7-3,7 mm compr. Ovário ca. $5 \mathrm{~mm}$ compr., 4-5 locular, $4 / 5$ a totalmente adnato ao hipanto, ápice cônico; estilete 5,5-7,8 mm compr. Cápsula ca. $11 \times 6 \mathrm{~mm}$; sementes ca. $0,9 \times 0,4 \mathrm{~mm}$.

Material selecionado: Arapoti, 27.XI.1959, G. Hatschbach 6548 (UPCB); Balsa Nova, 6.XI.2001, $R$. Goldenberg 534 (UPCB); Jaguariaíva, 2.XI.1998, O.S. Ribas 2770 (MBM); Lapa, 7.III.2002, O.S. Ribas 4539 (MBM); Palmeira, 4.II.1999, G. Hatschbach 68961 (MBM); Piraí do Sul, 24.I.2000, J. Carneiro 869 (MBM); Ponta Grossa, 22.V.1990, A.C. Cervi 3101 (MBM, UPCB); Porto Amazonas, 7.XII.1950, A. Mattos (UPCB 1351); São Luis do Purunã, 10.VII.2000, C.F. Alves 5 (HUCP); Tibagi, 13.VIII.2011, R. Goldenberg 1665 (RB, UPCB); Tijucas do Sul, 3.VI.1999, F.A. Cavalcanti 14 (HUCP).

Lavoisiera pulchella é encontrada em Minas Gerais, São Paulo e Paraná (Martins 2009b; Martins \& Rodrigues 2014a). Ocorre no Primeiro e Segundo Planaltos paranaenses. Geralmente coletada sobre solos arenosos, em regiões próximas a afloramentos de arenito. Coletada com flores e frutos de outubro a julho. Nos frutos maduros de $L$. pulchella, o hipanto é íntegro ou rompe-se do ápice para a base; neste aspecto, difere do padrão mais comum no gênero, onde o fruto todo (incluindo o hipanto) rompe-se a partir da base em direção ao ápice (Almeda \& Martins 2001). 
3. Microlicia D. Don, Mem. Wern. Soc. 4: 301. 1823.

Arbustos eretos. Folhas não imbricadas, sésseis ou subsésseis, com pontuações translúcidas. Flores isoladas; 5-meras. Hipanto sem coroa de tricomas no ápice. Pétalas lilases. Estames 10, dimórficos, estaminódios ausentes; anteras com o ápice rostrado. Ovário 3-locular, quase completamente livre; estilete glabro.

Microlicia é um gênero sul-americano (Brasil, Peru, Venezuela e Guiana), com aproximadamente 130 espécies, das quais 128 ocorrem no Brasil. Tem distribuição predominante no Brasil, em formações rupestres de Mato Grosso, Goiás, Distrito Federal, Bahia, e Minas Gerais, além Roraima, Amazonas, Pará, Maranhão, Piaú, Rondônia, Mato Grosso do Sul, Espírito Santo, Rio de Janeiro, São Paulo e Paraná. No Paraná é representado por 1 espécie. (Martins 2009a; Romero \& Woodgyer 2014).

3.1 Microlicia myrtoidea Cham., Linnaea 9: 393. 1834.

Fig. 1g-h

Arbustos $0,7-0,8 \mathrm{~m}$ alt.. Ramos jovens quadrangulares, glabros. Folhas sésseis ou com pecíolos até $0,3 \mathrm{~mm}$ compr.; lâmina 7-12 × 3-4 $\mathrm{mm}$, subcoriácea, oblongo-lanceolada, base arredondada, ápice agudo e arredondado, margem inteira a levemente crenada, 3 nervuras basais, ambas as faces glabras. Flores axilares e terminais. Hipanto ca. $4 \times 2 \mathrm{~mm}$, campanulado, glabro. Cálice com lacínias 1,8-2,1 mm compr., triangulares, ápice agudo com apículo terminal $0,4-0,7 \mathrm{~mm}$ compr., margem inteira, glabras. Pétalas ca. $7 \times 4$ $\mathrm{mm}$, oblongas, glabras. Estames maiores com filete ca. $3 \mathrm{~mm}$ compr., conectivo $2,2-3 \mathrm{~mm}$ compr., com apêndices ca. 1,5 mm. compr., antera ca. 2,7 $\mathrm{mm}$ compr.; estames menores com filete ca. 3 mm compr., conectivo $0,7-1,3 \mathrm{~mm}$ compr., com apêndices ca. $0,1 \mathrm{~mm}$ compr., antera ca. $2 \mathrm{~mm}$ compr. Ovário ca. $2 \mathrm{~mm}$ compr., ápice cônico; estilete ca. $4 \mathrm{~mm}$ compr. Cápsula ca. $4 \times 3 \mathrm{~mm}$; sementes $0,5-0,6 \times 0,3 \mathrm{~mm}$.

Material examinado: Sengés, 18.XI.1989, G. Hatschbach 53621 (MBM, UPCB).

Microlicia myrtoidea é encontrada apenas em São Paulo e Paraná, na região próxima à divisa entre os dois estados (Martins 2009a; Romero \& Woodgyer 2014). Coletada sobre solos arenosos, próximas a afloramentos de arenito. Coletada com flores e frutos em fevereiro e com botões, flores e frutos em junho, novembro e dezembro.
4. Rhynchanthera DC., Prodr. 3: 106. 1828.

Ervas a arbustos eretos. Folhas não imbricadas, sésseis ou pecioladas, sem pontuações translúcidas. Flores em cimeiras escorpioides; 5-meras. Hipanto sem coroa de tricomas no ápice. Pétalas brancas, lilases, magenta ou roxas. Estames férteis 5 , dimórficos ( 1 maior e 4 menores) ou isomórficos, estaminódios 5 , isomórficos; anteras com ápice rostrado. Ovário 3-5 locular, livre a curtamente adnato ao hpanto; estilete glabro ou com tricomas glandulares esparsos.

Rhynchanthera é um gênero com 15 espécies, que ocorrem desde o México até o Paraguai. No Brasil são 11 espécies, ocorrendo predominantemente em vegetação campestre em locais alagados, em vários estados. No Paraná é representado por 3 espécies (Renner 1990; Martins 2009c; Martins \& Rodrigues 2014c).

4.1 Rhynchanthera brachyrhyncha Cham., Linnaea 9: 379. $1834 . \quad$ Fig. 1.k-o

Arbustos $0,3-0,8 \mathrm{~m}$ alt.. Ramos jovens quadrangulares a subcilíndricos, densa a esparsamente recobertos por tricomas simples e/ ou glandulares. Folhas sésseis ou com pecíolos até $4 \mathrm{~mm}$ compr., lâmina $16-66 \times 11-38 \mathrm{~mm}$, membranácea, oblongo-lanceolada, cordada ou ovalada, base cuneada a cordada, ápice agudo, margem serreada, 5-7 nervuras basais, ambas as faces glabras ou esparsa a densamente recobertas por tricomas simples ou glandulares. Inflorescências 4-16 cm compr. Hipanto 3-4 × ca. $2 \mathrm{~mm}$, campanulado, glabro ou com tricomas glandulares esparsos. Cálice com lacínias ca. $4 \mathrm{~mm}$ compr., oblongo-subuladas, ápice agudo, margem inteira, glabras ou com tricomas glandulares na face externa. Pétalas $7-9 \times$ ca. $4 \mathrm{~mm}$, brancas ou rosadas a magenta, oblongo-lanceoladas, ápice agudo, com apículo terminando em um tricoma, glabras ou com alguns tricomas glandulares na margem. Estames férteis dimórficos, um deles até 2 vezes maior que os demais; estame maior com filete 3,3-5,5 $\mathrm{mm}$ compr., conectivo $0,4-5,8 \mathrm{~mm}$ compr., com apêndices $0,4-1,6 \mathrm{~mm}$ compr., antera com tecas $1,9-4,7 \mathrm{~mm}$ compr., rostro $0,4-1,5 \mathrm{~mm}$ compr.; estames menores com filete 2,4-3,3 mm compr., conectivo 1,3-2,3 mm compr., com apêndices $0,3-0,7 \mathrm{~mm}$ compr., antera com tecas $2,3-2,7 \mathrm{~mm}$ compr., rostro $0,3-0,6 \mathrm{~mm}$ compr.; estaminódios $5,2,3-3,8 \mathrm{~mm}$ compr. Ovário $2-3 \mathrm{~mm}$ compr., 3-locular, livre a $1 / 5$ adnato ao hipanto, ápice cônico com lobos; estilete $7-10$ mm compr., glabro 
ou recoberto por tricomas glandulares. Cápsula 3-5 $\times 3-4 \mathrm{~mm}$; sementes $0,5-0,9 \times 0,2-0,3 \mathrm{~mm}$.

Material selecionado: Balsa Nova, 12.III.1999, $R$. Goldenberg 495 (UPCB); Bocaiúva do Sul, 22.II.1962, G. Hatschbach 44319 (MBM); Campina Grande do Sul: 30.XII.1969, G. Hatschbach 23289 (MBM); Castro, 15.I.1965, G. Hatschbach 12132 (MBM); Curitiba, 30.I.1974, R. Kummrow 224 (MBM); Guarapuava, 13.II.1969, G. Hatschbach, 21175 (MBM); Lapa, I.1983, R. Campanholo (MBM 267082); Morretes, 29.I.2002, O.S. Ribas 4280 (MBM); Palmeira, 16.XI.1977, G. Hatschbach 40234 (MBM); Piraquara, 13.XII.1971, G. Hatschbach 28487 (MBM); Ponta Grossa, 13.I.1964, E. Pereira 8227 (MBM); Porto Amazonas, 11.II.1988, S. Ginzbarg 682 (UPCB); Quatro Barras, 15.I.1993, Y.S. Kuniyoshi (EFC 7371); São José dos Pinhais, 2.XII.1950, Tessmann 303 (MBM); 28.XII.1972, G. Hatschbach 31072 (MBM); São Mateus do Sul, 8.II.1966, G. Hatschbach 13767 (MBM); Tijucas do Sul, 10.I.1992, O.S. Ribas 395 (MBM); União da Vitória, 27.XII.1967, C. Koczicki 31 (MBM).

Rhynchanthera brachyrhyncha é encontrada em São Paulo, Paraná, Santa Catarina e Rio Grande do Sul (Renner 1990; Martins \& Rodrigues 2014b). Esta é a espécie que apresenta distribuição mais ampla no estado, sendo encontrada nos três planaltos paranaenses e Serra do Mar. Coletada em Floresta Ombrófila Densa e Floresta Ombrófila Mista, encosta de morros, vegetação ruderal, campos, brejos e locais úmidos. Coletada com botões e flores de janeiro a abril e com botões, flores e frutos de novembro a março.

4.2 Rhynchanthera cordata DC., Prodr. 3: 107. 1828.

Arbustos 0,7-1 m alt.. Ramos quadrangulares às vezes sulcados, densa a moderadamente recobertos por tricomas simples e/ou glandulares. Folhas com pecíolos 8-17 mm compr., lâmina 23-65 ×15-37 mm, membranácea, oblongo-lanceolada a cordada, base cuneada a cordada, ápice acuminado, margem irregularmente serrilhada, 5-9 nervuras basais; ambas as faces esparsa a moderadamente recobertas com tricomas simples, às vezes com a face adaxial glabra. Inflorescências 11-29 cm compr. Hipanto 5-6 × 3-4 mm, campanulado, glabro ou com tricomas simples e glandulares esparsos. Cálice com lacínias ca. 2,5 mm compr., triangulares, ápice agudo, margem inteira, com tricomas glandulares na face externa. Pétalas 7-17 × 4-7 mm, lilases a magenta, lanceoladas a oblongas, ápice agudo com apículo terminando em um tricoma, margem glabra. Estames dimórficos, um deles mais do que 2 vezes maior do que os demais; estame maior com filete $6,8-10,3 \mathrm{~mm}$ compr., conectivo 10,3-12,8 mm compr., apêndices 0,3-0,5 mm compr., antera com tecas 5,5-7,6 $\mathrm{mm}$ compr., rostro $0,7-1,3 \mathrm{~mm}$ compr.; estames menores com filete $3,8-6,4 \mathrm{~mm}$ compr., conectivo 1,9-4,6 mm compr., apêndices $0,3-0,6$ mm compr., antera com tecas 4,2-5,2 mm compr., rostro 0,6-1,7 mm compr.; estaminódios 5, 3,7-5,7 mm compr. Ovário 2-3 mm compr., 3-4-locular, livre a 1/5 adnato ao hipanto, ápice cônico, com ou sem lobos; estilete 20-27 mm compr. Cápsula ca. $5 \times 4 \mathrm{~mm}$; sementes ca. $0,8 \times 0,3 \mathrm{~mm}$.

Material selecionado: Arapoti, 22.III.1968, G. Hatschbach 18898 (MBM); Guaratuba, 27.II.1968, G. Hatschbach 18656 (MBM, UPCB); Jaguaraíva, 4.VI.1980, G. Hatschbach 43018 (MBM); Piraí do Sul, 5.III.1966, G. Hatschbach 14021 (MBM); Sengés, 12.II.1997, O.S. Ribas 1765 (MBM).

Material adicional examinado: BRASIL, Minas Gerais: Poços de Caldas, 10.III.1992, R.M. Britez 2183 (UPCB). Santa Catarina: Florianópolis, 12.IV.1994, D.B. Falkenberg 6655 (MBM).

Rhynchanthera cordata é encontrada em Minas Gerais, Rio de Janeiro, São Paulo, Paraná e Santa Catarina (Renner 1990; Martins \& Rodrigues 2014b). Ocorre no Litoral e Segundo Planalto paranaense. Coletada em capoeira, campos, brejos, locais úmidos e cerrado. Coletada com botões, flores e frutos em fevereiro e março.

4.3 Rhynchanthera dichotoma (Desr.) DC., Prodr. 3: 107.1828.

Arbustos 1-3 m alt. Ramos subcilíndricos a quadrangulares, densamente recobertos por tricomas simples e glandulares ou somente simples. Folhas com pecíolos 6-14 mm compr., lâmina 27-61 × 11-30 mm, membranácea, oblongo-lanceolada, base cordada, ápice agudo a acuminado, margem levemente serrilhada, 7-11 nervuras basais; ambas as faces moderadamente recobertas por tricomas simples. Inflorescências $13-23 \mathrm{~cm}$ compr. Hipanto $4-5 \times 2-3 \mathrm{~mm}$, campanulado, densamente recoberto por tricomas simples e glandulares. Cálice com lacínias 2,6-3,2 mm compr., subuladas a triangulares, ápice agudo, margem inteira a ciliada, glabra ou densamente recoberta por tricomas simples e glandulares na face externa. Pétalas $8-15 \times 6-9 \mathrm{~mm}$, roxas, obovadas, ápice agudo com apículo deslocado para um dos lados, tricomas esparsos na margem. Estames subisomórficos; filete 4,3-6,5 mm compr., conectivo 2,2-4,5 mm compr., com apêndices 0,4-0,5 mm compr., antera com tecas 3,7-4,2 mm 


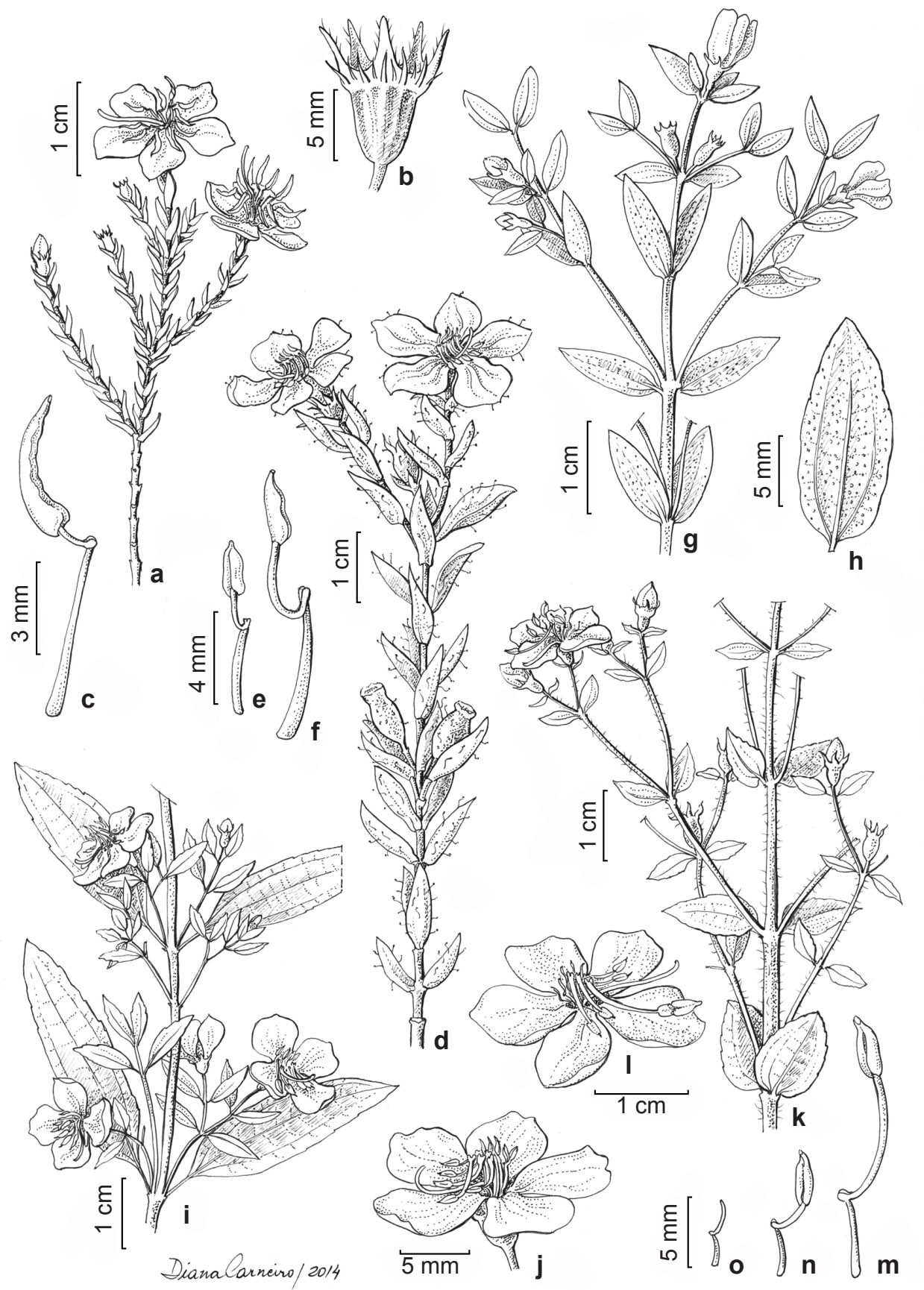

Figura 1 - a-o. Microlicieae (Melastomataceae) no Paraná. a-c. Chaetostoma armatum (Spreng.) Cogn. - a. Ramo fértil; b. Fruto jovem, mostrando a coroa de tricomas no ápice do hipanto; c. Estame não rostrado (Maia 37). d-f. Lavoisiera pulchella Cham. - d. Ramo fértil; e. Estame maior; f. Estame menor (Meyer 599). g-h. Microlicia myrtoidea Cham. - g. Ramo fértil; h. Folha com pontuações translúcidas (Hatschbach 5271). i-j. Trembleya parviflora (D.Don) Cogn. - i. Ramo fértil; j. Flor (Camargo 110). k-o. Rhynchanthera brachyrhyncha Cham. - k. Ramo fértil; 1. Flor; m. Estame maior; n. Estame menor; o. Estaminódio (Brotto 103).

Figure 1 - a-o. Microlicieae (Melastomataceae) in Paraná. a-c. Chaetostoma armatum (Spreng.) Cogn. - a. Fertile branch; b. Young fruit, with trichomes on the apex of the hypanthium; c. Stamen without a beak (Maia 37). d-f. Lavoisiera pulchella Cham. - d. Fertile branch; e. Larger stamen; f. Smaller stamen (Meyer 599). g-h. Microlicia myrtoidea Cham. - g. Fertile branch; h. Leaf with glandular dots (Hatschbach 5271). i-j. Trembleya parviflora (D.Don) Cogn. - i. Fertile branch; j. Flower (Camargo 110). k-o. Rhynchanthera brachyrhyncha Cham.. - k. Fertile branch; 1. Flower; m. Larger stamen; n. Smaller stamen; o. Staminode (Brotto 103). 
compr., rostro 0,3-0,4 mm compr.; estaminódios 5, 4,1-4,8 mm compr. Ovário 2-3 mm compr., 4-5-locular, livre, ápice cônico; estilete 13-17 mm compr., glabro ou recoberto por tricomas glandulares esparsos em sua base. Cápsula ca. $6 \times$ $5 \mathrm{~mm}$; sementes ca. $0,8 \times 0,3 \mathrm{~mm}$,

Material examinado: Campo Mourão, 12.IV.2005, D. Colombara (UPCB 52388).

Material adicional examinado: BRASIL, Minas Gerais: Caratinga, 13.XI.2001, M.O.D. Pivari 24 (UPCB); Santa Bárbara do Monte Verde, 21.V.2004, $K$. Antunes 118 (UPCB). Santa Catarina: Jaguaruna, 9.III.1984, T.M. Pedersen 13785 (MBM). São Paulo: Campinas, 26.III.1993, A.P. Spina 96 (UPCB); Matão, 14.IV.1994, V.C. Souza 5678 (UPCB).

Rhynchanthera dichotoma é encontrada em Roraima, Amazonas e Acre, além de Goiás, Bahia, Minas Gerais, Espírito Santo, Rio de Janeiro, São Paulo, Paraná e Santa Catarina (Renner 1990; Martins \& Rodrigues 2014b). Ocorre no Terceiro Planalto paranaense. Coletada em locais úmidos, em domínio de cerrado. Coletada com botões, flores e frutos em abril.

\section{Trembleya DC., Prodr. 3: 125. 1828.}

Ervas a arbustos eretos. Folhas não imbricadas, sésseis ou pecioladas, sem pontuações translúcidas. Flores em dicásios modificados; (4-)5-meras. Pétalas brancas ou rosadas. Estames 8-10, dimórficos, estaminódios ausentes; anteras com ápice rostrado. Ovário 5-locular, livre a curtamente adnato ao hipanto; estilete glabro.

Trembleya é um gênero exclusivamente brasileiro, com cerca de 14 espécies. A maioria das espécies ocorre em formações rupestres em Minas Gerais, e mais raramente em Mato Grosso, Goiás, Distrito Federal, Bahia, Espírito Santo, Rio de Janeiro, São Paulo e Paraná. No Paraná é representado por duas espécies (Martins 1997; Martins 2009b; Martins et al. 2014b).

5.1 Trembleya parviflora (D. Don) Cogn. in Mart., Eichl.\& Urban, Fl. bras. 14 (3): 128. 1883.

Fig. 1i-j

Arbustos 0,8-2,5 m alt. Ramos jovens subcilíndricos a quadrangulares, com tricomas simples ou glandulares. Folhas com pecíolos 2-10 mm compr.; lâmina $23-50 \times 6-16 \mathrm{~mm}$, discolor, cartácea a subcoriácea, lanceolada, base cuneada, ápice agudo, margem inteira ou revoluta, 3 nervuras basais, ambas as faces moderada a densamente recobertas com tricomas simples ou glandulares. Inflorescências laterais.
Flores (4-)5-meras. Hipanto 3-4 × ca. $2 \mathrm{~mm}$, oblongo a campanulado, com tricomas simples ou glandulares. Cálice com lacínias 1,3-3 mm compr., subuladas a triangulares, ápice agudo, margem inteira, com tricomas simples ou glandulares. Pétalas 7-11 × 4-7 mm, brancas, obovadas, glabras ou com tricomas simples. Estames 8-10; estames maiores com filete 3,7-5,3 mm compr., conectivo 2,3-2,8 mm compr., com apêndices 0,5-1,6 $\mathrm{mm}$ compr., antera com tecas 1,1-1,4 mm compr., rostro 0,2-0,4 mm compr.; estames maiores com filete $2,7-3,8 \mathrm{~mm}$ compr., conectivo 0,2-0,8 $\mathrm{mm}$ compr., com apêndices até $0,2 \mathrm{~mm}$ compr., antera com tecas $1-1,5 \mathrm{~mm}$ compr., rostro $0,2-0,4 \mathrm{~mm}$ compr. Ovário 2-3 $\mathrm{mm}$ compr., livre, ápice cônico a arredondado; estilete 2-4 mm compr. Cápsula ca. 4 × 3-4 mm; sementes ca. $0,5 \times 0,3 \mathrm{~mm}$.

Material selecionado: Antonina. 6.I.1992, G. Hatschbach 56167 (MBM); Arapoti, 20.III.1980, L.T. Dombrowski 11237 (UPCB); Balsa Nova, 21.IV.1980, G. Hatschbach 42967 (MBM); Bocaiúva do Sul, 8.IV.1998, J.M. Silva 2310 (MBM); Imbuial, 25.IV.1947, G. Hatschbach 44331 (MBM); Jaguaraíva, 20.IV.1989, G. Hatschbach 52830 (MBM); Palmeira, 10.III.1989, J.M. Silva 576 (MBM, UPCB); Piraí do Sul, 29.V.2012, R. Goldenberg 1652 (RB, UPCB); Ponta Grossa, 21.V.2000, D. Liebsch 13 (HUCP); Rio Branco do Sul, 27.III.1979, G. Hatschbach 42202 (MBM, UPCB); Sengés, 25.V.1977, G. Hatschbach 39594 (MBM); Tibagi, 27.X.2005, R. Goldenberg 824 (UPCB); Tunas, 18.IV.1995, J.M. Silva 1454 (MBM); Ventania, 22.III.2005, D.A. Estevan (FUEL, UPCB 50657).

Trembleya parviflora é encontrada em Goiás, Distrito Federal, Bahia, Minas Gerais, Espírito Santo, Rio de Janeiro, São Paulo e Paraná (Martins 2009b; Martins et al. 2014b). Ocorre no Litoral, Primeiro, Segundo e Terceiro Planaltos paranaenses. Geralmente coletada sobre solos arenosos, próximos a afloramentos de arenito, mas também em encostas úmidas, campos de altitude, floresta alto-montana, matas ciliares e cerrado. Coletada com flores e frutos em janeiro a março e com botões, flores e frutos de março e junho.

5.2 Trembleya phlogiformis DC., Prodr. 3: 126. 1828.

Ervas ou arbustos 0,3-0,5 m alt.. Ramos jovens subcilíndricos a quadrangulares, com tricomas simples e/ou glandulares. Folhas sésseis ou com pecíolos até $2 \mathrm{~mm}$ compr.; lâmina 25-48 $\times$ 7-14 mm, concolor, membranácea a cartácea, 
lanceolada, base cuneada, ápice agudo, margem inteira a serreada, 3-5 nervuras basais, ambas as faces moderada a esparsamente recobertas por tricomas simples e/ou glandulares. Inflorescências laterais ou terminais. Flores 5-meras. Hipanto 3-4 × ca. $2 \mathrm{~mm}$, campanulado, com tricomas glandulares. Cálice com lacínias 1,1-3,1 mm compr., triangulares a subuladas, ápice agudo, terminando em um tricoma, margem inteira, com tricomas simples e/ou glandulares. Pétalas 9-10 $\times$ 4-5 mm, rosadas, obovadas, glabras. Estames 10 ; estames maiores com filete 3,2-4 mm compr., conectivo 1,3-3,4 mm compr., com apêndices 1-1,2 mm compr., antera com tecas 1,4-1,9 mm compr., rostro 0,2-0,5 mm compr.; estames maiores com filete 1,9-4 mm compr., conectivo 1,1-1,2 mm compr., com apêndices $0,1-0,4 \mathrm{~mm}$ compr., antera com tecas 1,3-1,6 mm compr., rostro ca. 0,4 mm compr. Ovário 2-3 mm compr., ca. 1/3 adnado ao hipanto, ápice oval; estilete $4-5 \mathrm{~mm}$ compr. Cápsula ca. $5 \times 3 \mathrm{~mm}$; sementes ca. 0,5 × 0,2 mm. Material examinado: Bocaiúva do Sul, 18.II.1999, J.M. Silva 2875 (MBM); Campina Grande do Sul, 24.I.1968, G. Hatschbach 18429 (MBM, UPCB); Curitiba, 30.I.1974, R. Kummrow 223 (MBM); Jaguariaíva, 3.III.1966, G. Hatschbach 13964 (MBM, UPCB); Sengés. 28.II.1972, G. Hatschbach 29252 (MBM); Tibagi, 26.III.2004, M.R.B. do Carmo 863 (UPCB).

Material adicional examinado: BRASIL, Distrito Federal: Brasília, 19.VII.1989, F. França (UPCB 20225). Minas Gerais: Baependi, 8.III.2003, F.M. Ferreira 424 (UPCB); Funil, 11.IV.2004, K. Antunes 82 (UPCB). São Paulo: Campos do Jordão, 13.II.2004, F.A.R.D.P. Arzolla 467 (UPCB).

Trembleya phlogiformis é encontrada no Mato Grosso, Goiás, Distrito Federal, Bahia, Minas Gerais, Espírito Santo, Rio de Janeiro, São Paulo e Paraná (Martins 2009b; Martins et al. 2014b). Ocorre no Primeiro e Segundo Planaltos paranaenses. Geralmente coletada sobre solos arenosos, próximos a afloramentos de arenito, e em cerrado. Coletada com botões, flores e frutos de janeiro a março.

\section{Agradecimentos}

Este trabalho é parte da monografia de bacharelado da terceira autora. O primeiro e segundo autores receberam bolsas, respectivamente, de CNPQ (produtividade em pesquisa) e CAPES (mestrado). Parte deste trabalho foi financiada pelo CNPQ (Protax 562210/2010-5).

\section{Referências}

Almeda, F. \& Martins, A.B. 2001. New combinations and new names in some brazilian Microlicieae (Melastomataceae), with notes on the delimitation of Lavoisiera, Microlicia, and Trembleya. Novon 11: 1-7.

Amorim, A.M.; Goldenberg, R. \& Michelangeli, F. 2009. A new species of Physeterostemon (Melastomataceae) from Bahia, Brazil, with notes on the phylogeny of the genus. Systematic Botany 34: 324-329.

Baumgratz, J.F.A.; Rodrigues, K.F.; Chiavegatto, B.; Goldenberg, R.; Guimarães, P.J.F.; Kriebel, R.; Martins, A.B.; Michelangeli, F.A.; Reginato, M.; Romero, R.; Souza, M.L.D.R.; Woodgyer, E.; Caddah, M.K.; Koschnitzke, C.; Lima, L.F.G. \& Rosa, P. 2014 Melastomataceae. In: Lista de Espécies da Flora do Brasil. Jardim Botânico do Rio de Janeiro. Disponível em $<$ http://floradobrasil. jbrj.gov.br/jabot/floradobrasil/FB161>. Acesso em abril de 2014.

Clausing, G. \& Renner, S.S. 2001. Molecular phylogenetics of Melastomataceae and Memecylaceae: implications for character evolution. American Journal of Botany 88: 486-498.

Cogniaux, A. 1883-1885. Melastomataceae. In: Martius, C.F.P. von; Eichler, A.W. \& Urban, I. (eds.) Flora brasiliensis. Lipsae, Munchen. Vol. 14(3), pp. 6-510.

Cogniaux, A 1891. Melastomataceae. In: Candolle, A. \& Candolle, C. (eds.). Monographiae Phanerogamarum. Vol. 7. G. Masson, Paris. Pp. 1-1256.

Fritsch, P.W.; Almeda, F.; Renner, S.S.; Martins, A.B. \& Cruz, B.C. 2004. Phylogeny and circumscription of the near-endemic Brazilian tribe Microlicieae (Melastomataceae). American Journal of Botany 91: 1105-1114

Goldenberg, R.; Baumgratz, J.F.A. \& Souza, M.L.D.R. 2012a. Taxonomia de Melastomataceae no Brasil: retrospectiva, perspectivas e chave de identificação para os gêneros. Rodriguésia 63: 145-161.

Goldenberg, R.; Fraga, C.N.; Fontana, A.P.; Nicolas, A. \& Michelangeli, F.A. 2012b. Taxonomy and Phylogeny of Merianthera (Melastomataceae). Taxon 65: 1040-1056.

Koschnitzke, C. 2009. Chaetostoma DC. In: Martins, S.E.; Wanderley, M.G.L.; Shepherd, G.J.; Giulietti, A.M. \& Melhem, T.S. (eds.). Flora fanerogâmica do estado de São Paulo. Vol. 6. Instituto de Botânica, São Paulo. Pp. 17-19.

Koschnitzke, C. \& Martins, A.B. 2006. Revisão taxonômica de Chaetostoma DC. (Melastomataceae, Microlicieae). Arquivos do Museu Nacional 64: 95-119.

Labiak, P.H. 2014. Aspectos fitogeográficos do Paraná. In: Kaehler, M. et al. (eds.). Plantas Vasculares do Paraná. UFPR, Curitiba. Pp. 7-22. 
Maack, R. 1981. Geografia física do estado do Paraná. BADEP/UFPR/IBTP, Curitiba. 350p.

Martins, A.B. 2009a. Melastomataceae. In: Martins, S.E.; Wanderley, M.G.L.; Shepherd, G.J.; Giulietti, A.M. \& Melhem, T.S. (eds.). Flora fanerogâmica do estado de São Paulo. Vol. 6. Instituto de Botânica, São Paulo. Pp. 1-167.

Martins, A.B. 2009b. Lavoisiera DC. In: Martins, S.E.; Wanderley, M.G.L.; Shepherd, G.J.; Giulietti, A.M. \& Melhem, T.S. (eds.). Flora fanerogâmica do estado de São Paulo. Vol. 6. Instituto de Botânica, São Paulo. Pp. 29-30.

Martins, A.B. 2009c. Rhynchanthera DC. In: Martins, S.E.; Wanderley, M.G.L.; Shepherd, G.J.; Giulietti, A.M. \& Melhem, T.S. (eds.). Flora fanerogâmica do estado de São Paulo. Vol. 6. Instituto de Botânica, São Paulo. Pp. 120-124

Martins, A.B. \& Rodrigues, K.F. 2014a. Lavoisiera. In: Lista de Espécies da Flora do Brasil. Jardim Botânico do Rio de Janeiro. Disponível em $<$ http://floradobrasil.jbrj.gov.br/jabot/floradobrasil/ FB9492>. Acesso em novembro de 2014.

Martins, A.B. \& Rodrigues, K.F. 2014 b. Rhynchanthera. In: Lista de Espécies da Flora do Brasil. Jardim Botânico do Rio de Janeiro. Disponível em <http://floradobrasil.jbrj.gov.br/ jabot/floradobrasil/FB9860>. Acesso em novembro de 2014.

Martins, A.B. \& Rodrigues, K.F. $2014 \mathrm{c}$. Stenodon. In: Lista de Espécies da Flora do Brasil. Jardim Botânico do Rio de Janeiro. Disponível em: $<$ http://floradobrasil.jbrj.gov.br/jabot/floradobrasil/ FB30822>. Acesso em novembro de 2014.

Martins, A.B.; Rodrigues, K.F.; Koschnitzke, C. \& SilvaGonçalves, K.C. 2014a. Chaetostoma. In: Lista de Espécies da Flora do Brasil. Jardim Botânico do Rio de Janeiro. Disponível em $<$ http://floradobrasil. jbrj.gov.br/jabot/floradobrasil/FB9436>. Acesso em novembro de 2014.

Martins, A.B.; Rodrigues, K.F. \& Silva-Gonçalves, K.C. 2014b. Trembleya. In: Lista de Espécies da Flora do Brasil. Jardim Botânico do Rio de Janeiro.
Disponível em <http://floradobrasil.jbrj.gov.br/ jabot/floradobrasil/FB9979>. Acesso em novembro de 2014.

Martins, E. 1997. Revisão taxonômica do gênero Trembleya DC. (Melastomataceae). Tese de Doutorado. Universidade Estadual de Campinas, São Paulo. 162p.

Martins, E. 2009a. Microlicia D.Don. In: Martins, S.E.; Wanderley, M.G.L.; Shepherd, G.J.; Giulietti, A.M. \& Melhem, T.S. (eds.). Flora fanerogâmica do estado de São Paulo. Vol. 6. Instituto de Botânica, São Paulo. Pp. 105-108.

Martins, E. 2009b. Trembleya DC. In: Martins, S.E.; Wanderley, M.G.L.; Shepherd, G.J.; Giulietti, A.M. \& Melhem, T.S. (eds.). Flora fanerogâmica do estado de São Paulo. Vol. 6. Instituto de Botânica, São Paulo. Pp. 150-153

Michelangeli, F.A.; Guimarães, P. J. F.; Penneys, D. S.; Almeda, F. \& Kriebel, R. 2013. Phylogenetic relationships and distribution of New World Melastomeae (Melastomataceae). Botanical Journal of the Linnean Society 171: 38-60.

Penneys, D.S.; Michelangeli, F.A.; Judd, W.S. \& Almeda, F. 2010. Henrietteeae (Melastomataceae): a new neotropical berry-fruited tribe. Systematic Botany 35: 783-800.

Renner, S.S. 1990. A revision of Rhynchanthera (Melastomataceae). Nordic Journal of Botany 9: 601-630.

Renner, S.S. 1993. Phylogeny and classification of the Melastomataceae and Memecylaceae. Nordic Journal of Botany 13: 519-540.

Romero, R. \& Woodgyer, E. 2014. Microlicia. In: Lista de Espécies da Flora do Brasil. Jardim Botânico do Rio de Janeiro. Disponível em $<$ http://floradobrasil. jbrj.gov.br/jabot/floradobrasil/FB9782>. Acesso em novembro de 2014.

Thiers, B. continuously updated. Index Herbariorum: a global directory of public herbaria and associated staff. New York Botanical Gardens's Virtual Herbarium. Disponível em $<$ http://sweetgum.nybg. org/ih/>. Acesso em maio de 2014. 
Lista de exsicatas:

Abe, L.M. 3 (4.1). Almeida, L.K.M. UPCB 27506 (2.2). Alves, C.F. 5 (2.2). Annan, H.M. UPCB 27513 (5.1). Barbosa, E. 867 (2.2). Bassani, G. 2 (2.2). Brotto, M.L. 103 (4.1). Buim, M.E. FUEL 14179 (1.1). Caddah, M.K. 671 (1.1). Camargo, E.A. 110 (5.1). Campanholo, R. MBM 267082 (4.1). Carmo, M.R.B. 863 (5.2). Carneiro, J. 869 (2.2). Cavalcanti, F.A. 14 (2.2). Caxambu, M.G. 605 (2.2), Cervi, A.C. 3101 (2.2), 3775 (2.1), 3810 (5.1), 3990 (5.1), 4010 (1.1), 4103 (5.1), 4087 (5.1), 6134 (2.1), 6145 (2.1), 6267 (5.1), 6813 (5.1), UPCB 19222 (2.2). Carneiro, J. 942 (5.1). Carrião, D.J.S. 52 (2.2). Colombara, D. UPCB 52388 (4.3). Cordeiro, J. 525 (2,2), 605 (4.1), 684 (2.2). Dombrowski, L.T. 11237 (5.1). Dunaiski Jr. 1115 (2.2). Dusén, P. 11694 (2.1.), 14815 (2.1). Espindola, A.B. 9 (2.1). Estevan, D.A. 1020 (1.1), UPCB 50642 (2.1), UPCB 50657 (5.1). Ferrucci, S. 242 (4.1). Ginzbarg, S. 682 (4.1). Goldenberg, R. 493 (2.2.), 495 (4.1), 534 (2.2), 814 (2.2), 819 (1.1), 820 (2.1), 824 (5.1), 1651 (2.1), 1652 (5.1), 1653 (1.1), 1655 (2.2), 1665 (2.2). Hatschbach, G. 205 (2.2), 697 (5.1), 1159 (5.1), 2775 (5.1), 3625 (1.1), 3626 (2.1), 3850 (5.1), 3852 (2.2), 4507 (4.1), 5271 (3.1), 6032 (5.1.), 6128 (2.1), 6548 (2.2); 6754 (4.1), 6793 (2.2), 6833 (4.2), 6909 (1.1), 8088 (5.1), 8227 (4.1), 8665 (4.1), 9070 (5.1.), 9694 (2.2), 9714 (4.1), 11263 (2.2), 12132 (4.1), 13493 (2.2), 13494 (4.1), 13767 (4.1), 13925 (1.1), 13927 (2.2), 13929 (2.1), 13949 (4.1), 13930 (5.1), 13964 (5.2), 13974 (4.2), 14021 (4.2), 18429 (5.2), 18656 (4.2), $18856(1.1), 18843$ (5.1), 18898 (4.2), 18928 (2.1), 18968 (5.1), 20419 (2.2), 20694 (4.1), 21175 (4.1), 23219 (2.2), 23289 (4.1), 24106 (1.1), 24132 (5.1), 25736 (4.1), 26193 (4.1), 26725 (3.1), 26721 (5.1), 28487 (4.1), 29249 (1.1); 29252 (5.2), 31072 (4.1), 31097 (1.1), 31164 (2.1), 35767 (4.1), 37933 (4.1), 39195(2.2), 39594 (5.1), 39960 (1.1), 40234 (4.1), 40238 (2.2), 41912 (4.1), 42202 (5.1), 42652 (2.2), 42967 (5.1), 43018 (4.2), 44319 (4.1), 44331 (5.1), 45728 (2.2), 49351 (5.1), 50905 (1.1), 51934 (2.1), 51936 (5.1), 52830 (5.1), 51969 (1.1), 52818 (5.1), 53621 (3.1), 56167 (5.1), 58174 (2.2), 58177 (1.1), 67093 (2.2), 68961 (2.2). Hauer, L. 1 (2.2). Klein, E.F. 5 (4.1). Koczicki, C. 31 (4.1). Kummrow, R. 223 (5.2), 224 (4.1), 459 (1.1), 1092 (2.2), 1748 (2.2), 2879 (4.1). Kuniyoshi, Y.S. 5161 (2.1), 5180 (5.1), 5511 (2.2), 5520 (1.1), 5471 (5.1), 5522 (2.1), EFC 7371 (4.1). Landrum, L.R. 2518 (2.2), 2523 (4.1). Lange, R.B. 1101 (4.1). Langohr, M.I. 54 (4.1). Laroca, S. UPCB 19692 (4.1). Lewis G.P. 1375 (4.1). Liebsch, D. 13 (5.1). Lindeman, J. 421 (4.1), 4598 (4.1). Lisingen, Von. 127 (4.2), 135 (2.1). Longhi-Wagner, H.M. 8979 (2.2). Meyer, F.S. 599 (2.2). Maia, F.R. 33 (1.1), 34 (2.1), 37 (1.1), 43 (5.1), 79 (2.2), 89 (1.1). Mattos, A. UPCB 1351 (2.2). Noschang, J. UPCB 27505 (1.1). Oliveira, P.I. 1021 (4.1). Pereira, E. 5532 (4.1), 8281 (2.2), 8227 (4.1). Portes, M.C. 88 (2.1), 91 (5.1). Ribas, O.S. 393 (4.1), 395 (4.1), 517 (5.1), 1385 (1.1), 1652 (2.1), 1722 (1.1), 1765 (4.2), 1769 (3.1), 1894 (2.2), 2770 (2.2), 2813 (2.2), 3457 (2.2), 4280 (4.1), 4539 (2.2), 5036 (1.1), 6769 (5.1). Roderjan, C.V. 628 (1.1), 1199 (5.1), 1348 (2.1), 1673 (1.1). Santos, M.C. 1 (2.1). Silva, B. 90 (2.2). Silva. J.M. 1001 (4.1), 1080 (2.2), 1946 (5.1), 3376 (5.1), 4256 (5.1). Silva, S.M. 576 (5.1), 1454 (5.1), 2310 (5.1), 2875 (5.2), UPCB 22983 (1.1), UPCB 22984 (2.2), UPCB 24530 (2.2), UPCB 27503 (1.1), UPCB 27504 (1.1), UPCB 34056 (2.1), UPCB 34066 (2.1), UPCB 27509 (5.1), UPCB 27511 (5.1), UPCB 27512 (5.1). Silveira, M. 70 (3.1). Smythe, A. 4 (2.1). Stehmann, J.R. 2248 (1.1), 2253 (2.2). Stepherd, S.J. 6158 (2.2). Tardivo, R.C. (5.1). Tessmann, G. 303 (4.1). Uhlmann, A. 110 (5.1). Vieira, A.O.S. 12236 (4.1). Vieira, M.E.M. 19 (2.2), 26 (1.1). Ziller, S.R. 444 (4.1), 1495 (2.1), 1567 (5.1), 1575 (2.1). 